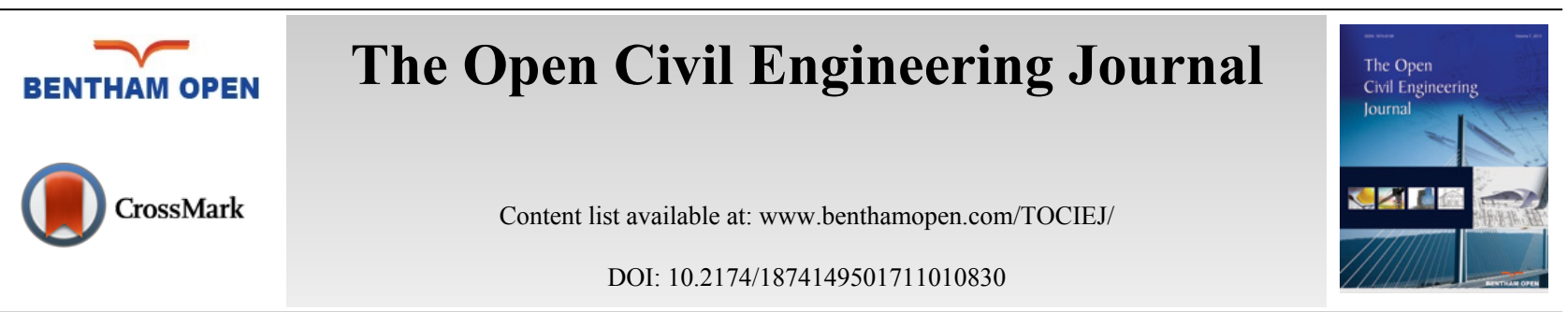

EDITORIAL

\title{
Mechanics Property of the Engineering Structure
}

This special issue named "Mechanics Property of the engineering Structure" includes seismic behavior, fire resistance and ultimate capacity etc. follows the last very successful special issue in 2014. In the last decade, substantial progress has been made in Mechanics Property Analysis in the field of the engineering Structure, presentation and analysis to facilitate the development of large-scale building constructions. Together with the maturation and development of structural elements like shear wall, RC Beam, CFST column, and the beam-column joint, it is now possible to build a new generation of complicated structure types. However, there is still a long way to go for mature solutions of structure suffered fire or earthquake etc. It could be even more challenging. Therefore, the goal of this special issue is to invite high quality contributions in the mechanics analysis of engineering structure, with a focus on how to apply experimental and theoretical methods to analyze the mechanics property of engineering structure.

As the guest editor of this special issue of The Open Civil Engineering Journal, I would like to thank some people who made this issue possible. First thanks to the Editorial Manager, Ms. Shah Bano, for her management of the thematic issue and her interest in this topic. Finally, I sincerely thank the contributors and reviewers of the submitted papers.

Guest Editor

Mingjin Chu

Beijing Advanced Innovation Center for Future Urban Design Beijing University of Civil Engineering and Architecture,

This is an open access article distributed under the terms of the Creative Commons Attribution 4.0 International Public License (CC-BY 4.0), a copy of which is available at: https://creativecommons.org/licenses/by/4.0/legalcode. This license permits unrestricted use, distribution, and reproduction in any medium, provided the original author and source are credited. 